\title{
Waterpipe smoking, a form of tobacco consumption that is on the rise
}

\author{
Stella Regina Martins ${ }^{1, a}$, Ubiratan de Paula Santos ${ }^{1, b}$
}

The waterpipe apparatus (also known as shisha, hookah, or narghile), used mainly in North African and Asian countries, probably originated in India in the 16th century. ${ }^{(1)}$ Tobacco smoking using a waterpipe has been increasing worldwide and, especially among young people, has become epidemic. (2)

A study involving more than 11,000 US Air Force military recruits revealed that $28 \%$ had used a waterpipe in their lifetime and $10 \%$ had used it in the past month. Waterpipe use was higher among cigarette smokers, younger individuals, and single individuals. ${ }^{(3)}$

In the current issue of the JBP, Araújo et al.(4) report on a survey of third- and sixth-year students at a medical school in the state of Goiás, Brazil, which, although involving a small number of students, revealed a worrying situation. The prevalence of waterpipe experimentation was found to be about $60 \%$, with one third of students reporting having used a waterpipe in the past six months and $28 \%$ reporting having used it in the past 30 days. The prevalence was higher among smokers (80\%) and among those who consumed alcohol (72\%). Most students were aware that waterpipe smoking is harmful; this proportion was higher among sixth-year students. However, despite their greater knowledge of the attendant risks, there were no differences in the prevalence of use. These data reveal a higher prevalence than that reported in the aforementioned study of recruits ${ }^{(3)}$ and that reported in a survey of medical students at a Brazilian university. ${ }^{(5)}$

In Brazil, there have been few population-based studies of the prevalence of waterpipe use. In the period between May and December of 2015, a study of 16,273 individuals aged 12 to 65 years was conducted, through face-to-face interviews, in 26 state capitals and the Federal District of Brasília. ${ }^{(6)}$ The results showed that the overall proportion of waterpipe use in the past 12 months was $1.65 \%$, which corresponds to approximately 2.5 million individuals. Among younger people (12- to 24 -year-olds) who reported being smokers, $18.96 \%$ had smoked a waterpipe in the past 12 months, whereas among nonsmokers, that proportion was $2.71 \%$. That same study revealed that the prevalence of waterpipe use, as compared with that of cigarette use, is highest among young people of high socioeconomic status and in the non-heterosexual population. ${ }^{6}$

For many centuries, waterpipe smoking was seen as a safer form of tobacco smoking and as being less harmful to health. However, the currently available scientific evidence no longer supports this hypothesis. ${ }^{(7)}$ An important factor in the increasing use of waterpipes is the misperception of safety, supported, on the one hand, by the belief that the toxic substances would be filtered by the water in the waterpipe and, on the other hand, by the fact that waterpipes are smoked less frequently than cigarettes, given that their use is impractical during usual activities. Increasingly extensive and intensive advertising, easy access, inclusion of additives with numerous attractive flavors and aromas in the tobacco, and peer group smoking behavior are other major determinants. ${ }^{(8)}$

We know that, during waterpipe use, there occurs not only the burning of coal but also the incomplete combustion of tobacco, given that waterpipe combustion occurs at a temperature close to $500^{\circ} \mathrm{C}$, which is lower than the combustion temperature of conventional cigarettes. At that temperature, high concentrations of toxicants are released into the air and are inhaled by waterpipe users and by those who are in the same environment not only at the time of use, because deposited carcinogenic particulate matter remains in the venue for days. ${ }^{(9)}$

About 300 chemicals have been identified in waterpipe smoke. ${ }^{(10)}$ Among those chemicals, there are 82 toxic substances, 23 of which are carcinogenic, including polycyclic aromatic hydrocarbons, heterocyclic compounds, primary aromatic amines, $\mathrm{N}$-heterocyclic amines, tobacco-specific nitrosamines, and metals, responsible for cardiopulmonary diseases and cancer, as well as nicotine, which causes dependence. ${ }^{(8)}$

On the market, there are numerous tobacco and non-tobacco products available for use in waterpipes. The products that are labeled as not containing tobacco, also known as herbal products, are nicotine free. On the labels of herbal products, which are marketed as being "a healthier alternative to waterpipe tobacco", we find the descriptors "tobacco free", " $0 \%$ nicotine", and "0\% tar," which makes them more attractive to young people. ${ }^{(9)}$ However, research has shown that herbal products are sweetened with sugarcane, which forms molasses. Upon heating, high levels of carcinogenic volatile aldehydes are generated in the smoke. ${ }^{(11)}$ The only difference found in mainstream waterpipe smoke between tobacco and non-tobacco products was the absence of nicotine in the latter. All other toxic and carcinogenic substances, such as tar, carbon monoxide, nitric oxide, fluoranthene, pyrene, formaldehyde, acetaldehyde, and acetone, were present at equal or higher concentrations in herbal products compared with tobacco products. ${ }^{(8)}$

Findings from countless research studies and data from studies conducted in Brazil, ${ }^{(5,6)}$ as well as those published in the current issue of the $\mathrm{BPP}_{1}{ }^{(4)}$ underscore the need for further measures, based on the articles of the World Health Organization Framework Convention 
on Tobacco Control, which was ratified by Brazil in $2005,{ }^{(12)}$ to protect current and future generations from the harms of waterpipe smoking. Among the recommended measures are a ban on symbols, images, and words that lead to the erroneous conclusion that waterpipes and waterpipe products and accessories are less harmful to health; a ban on attractive additives; a ban on waterpipe venues and the sale of waterpipes and waterpipe products near schools; and the addition of warning labels about the harms of waterpipe use to the waterpipe itself and to waterpipe accessories. It is also essential to raise awareness of and educate health care professionals, educators, and the general public about the health hazards caused not only by waterpipe smoking (of tobacco or non-tobacco products) but also by new classes of tobacco products, such as electronic cigarettes and heated tobacco products, with which the tobacco industry is attempting to reverse the global decline in the prevalence of smoking. ${ }^{(7,13-15)}$

\section{REFERENCES}

1. World Health Organization [homepage on the Internet]. Geneva: WHO. Tobacco Free Initiative. WHO Study Group on Tobacco Product Regulation (TobReg) [cited 2019 Jul 1]: Advisory Note: Waterpipe Tobacco Smoking: Health Effects, Research Needs and Recommended Actions by Regulators; 2005. [Microsoft Word document, 20p.]. Available from: http://www.who.int/tobacco/ global_interaction/tobreg/Waterpipe\%20recommendation_Final. pdf?ua $=1$

2. Maziak W. The global epidemic of waterpipe smoking. Addict Behav 2011;36(1-2):1-5. https://doi.org/10.1016/j.addbeh.2010.08.030

3. Linde BD, Ebbert JO, Pasker CK, Wayne Talcott G, Schroeder DR, Hanson $A C$, et al. Prevalence and predictors of hookah use in US Air Force military recruits. Addict Behav. 2015;47:5-10. https://doi. org/10.1016/j.addbeh.2015.03.012

4. Araújo RS, Milhomem YO, Pereira HFS, Silva Junior JLR. Factors related to the use of hookah among medical students. J Bras Pneumol. 2019;45(5):e20180184. https://dx.doi.org/10.1590/18063713/ e20180184

5. Martins SR, Paceli RB, Bussacos MA, Fernandes FL, Prado GF Lombardi EM, et al. Experimentation with and knowledge regarding water-pipe tobacco smoking among medical students at a major university in Brazil. J Bras Pneumol. 2014;40(2):102-10. https://doi. org/10.1590/S1806-37132014000200002

6. Bertoni N, Szklo A, Boni RD, Coutinho C, Vasconcellos M, Nascimento Silva $P$, et al. Electronic cigarettes and narghile users in Brazil: Do they differ from cigarettes smokers? Addict Behav. 2019;98:106007. https://doi.org/10.1016/j.addbeh.2019.05.031

7. Brasil. Ministério da Saúde. Instituto Nacional de Câncer José Alencar Gomes da Silva [homepage on the Internet]. Rio de Janeiro: INCA c2019 [cited 2019 Sep 1]. Narguilé: o que sabemos? [Adobe Acrobat document, 102p.]. Available from: https://www.inca.gov.br/sites/ufu sti.inca.local/files//media/document//narguile-o-que-sabemos.pdf

8. Shihadeh A, Schubert J, Klaiany J, El Sabban M, Luch A, Saliba NA. Toxicant content, physical properties and biological activity of waterpipe tobacco smoke and its tobacco-free alternatives.
Tob Control. 2015;24 Suppl 1:i22-i30. https://doi.org/10.1136/ tobaccocontrol-2014-051907

9. Torrey CM, Moon KA, Williams DA, Green T, Cohen JE, Navas-Acien A, et al. Waterpipe cafes in Baltimore, Maryland: Carbon monoxide, particulate matter, and nicotine exposure. J Expo Sci Environ Epidemiol. 2015;25(4):405-10. https://doi.org/10.1038/jes.2014.19

10. Hammal F, Chappell A, Wild TC, Kindzierski W, Shihadeh A, Vanderhoek $A$, et al. 'Herbal' but potentially hazardous: an analysis of the constituents and smoke emissions of tobacco-free waterpipe products and the air quality in the cafés where they are served. Tob Control. 2015;24(3):290-7. https://doi.org/10.1136/ tobaccocontrol-2013-051169

11. Monzer B, Sepetdjian E, Saliba N, Shihadeh A. Charcoal emissions as a source of $\mathrm{CO}$ and carcinogenic $\mathrm{PAH}$ in mainstream narghile waterpipe smoke. Food Chem Toxicol. 2008;46(9):2991-5. https:// doi.org/10.1016/j.fct.2008.05.031

12. Ministério da Saúde. Instituto Nacional de Câncer. ConvençãoQuadro para o Controle do Tabaco. Texto oficial. Rio de Janeiro: INCA; 2011.

13. Hoffman SJ, Mammone J, Rogers Van Katwyk S, Sritharan L, Tran M, Al-Khateeb S, et al. Cigarette consumption estimates for 71 countries from 1970 to 2015: systematic collection of comparable data to facilitate quasi-experimental evaluations of national and global tobacco control interventions. BMJ. 2019;365:I2231. https:// doi.org/10.1136/bmj.I2231

14. Levy D, de Almeida LM, Szklo A. The Brazil SimSmoke policy simulation model: the effect of strong tobacco control policies on smoking prevalence and smoking-attributable deaths in a middle income nation. PLoS Med. 2012;9(11):e1001336. https://doi. org/10.1371/journal.pmed.1001336

15. GBD 2015 Tobacco Collaborators. Smoking prevalence and attributable disease burden in 195 countries and territories, 19902015: a systematic analysis from the Global Burden of Disease Study 2015. Lancet. 2017;389(10082):1885-1906. https://doi.org/10.1016/ S0140-6736(17)30819-X 